\title{
Streptococcal Throat Carriage among Primary School Children Living in Uyo, Southern Nigeria
}

\author{
Kevin B. Edem ${ }^{1} \quad$ Enobong E. Ikpeme ${ }^{1} \quad$ Mkpouto U. Akpan ${ }^{1}$ \\ ${ }^{1}$ Department of Paediatrics, University of Uyo Teaching Hospital, \\ Uyo, Akwa Ibom State, Nigeria \\ J Child Sci 2021;11:e28-e34. \\ Address for correspondence Kevin Bassey Edem, MBBCH, FWACP, \\ Department of Paediatrics, University of Uyo Teaching Hospital, PMB \\ 1136, Uyo, Akwa Ibom State, Nigeria \\ (e-mail: edemkevin@gmail.com).
}

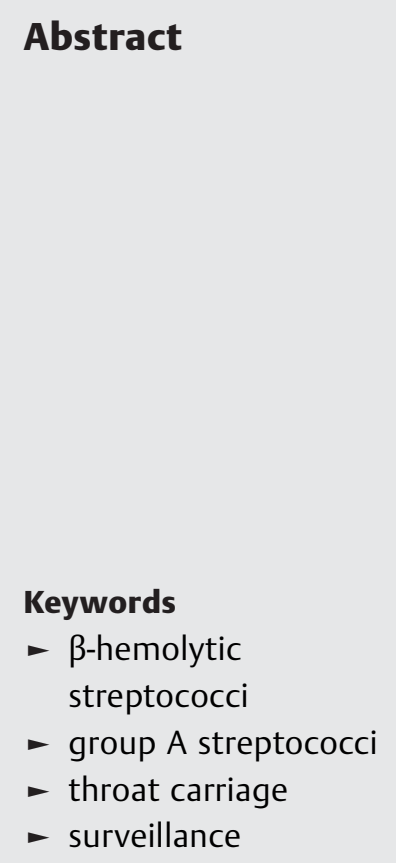

Surveillance of the carrier state for $\beta$-hemolytic streptococcal (BHS) throat infections remains essential for disease control. Recent published works from Sub-Saharan Africa have suggested a changing epidemiology in the burden of BHS throat infections. The objective of the present study was therefore to determine the prevalence and pattern of BHS throat carriage in school-aged children in Uyo, Akwa Ibom State. This was a prospective crosssectional study of 276 primary school children in Uyo. Subjects were recruited by multistage random sampling. Obtained throat swabs were cultured on $5 \%$ sheep blood agar. Lancefield grouping on positive cultures was done by using the Oxoid Streptococcal Grouping Latex Agglutination Kit, United Kingdom. Antimicrobial susceptibility testing was done with the disk diffusion method. Associations were tested with Fischer's exact test. The prevalence of BHS carriage was 3.3\%. Group C Streptococcus was identified in $89 \%$ of isolates and Group G Streptococcus in $11 \%$. Younger age and larger household size were associated with asymptomatic streptococcal throat infections. Antimicrobial susceptibility was highest with cefuroxime and clindamycin (89\% of isolates each), while $78 \%$ of isolates were susceptible to penicillin. None of the tested isolates was susceptible to co-trimoxazole. The prevalence of streptococcal throat carriage in the study area was low. There were no Group A Streptococcus isolates suggesting an evolving epidemiology of BHS disease in the study area.

\section{Introduction}

Group A Streptococcus (GAS) is an important cause of infectious disease mortality, accounting for up to half a million deaths annually. ${ }^{1-3}$ It is the most commonly isolated bacterial agent in acute pharyngitis and accounts for 15 to $30 \%$ of all throat infections. ${ }^{3-6}$ However, $\beta$ hemolytic streptococci (BHS) have also been isolated from asymptomatic individuals, who serve as reservoirs of infection in the community. ${ }^{7,8}$ Active surveillance of BHS disease may thus be achieved by periodic evaluation of the prevalence of streptococcal throat carriage in a community..$^{8-10}$

Streptococcal throat infection may be complicated by early suppurative as well as medium and long-term non-

received

September 10, 2020

accepted after revision

November 27, 2020
DOI https://doi.org/

$10.1055 / \mathrm{s}-0040-1722274$.

ISSN 2474-5871. suppurative sequelae such as acute rheumatic fever and poststreptococcal glomerulonephritis, with high morbidity and mortality. ${ }^{11,12}$ Rheumatic heart disease affects over 15 million persons worldwide, causing about a quarter of a million deaths annually, with highest prevalence recorded in SubSaharan Africa. ${ }^{13,14}$ While rheumatic fever is described in carriers, recurrent rheumatic fever episodes, with higher risk of rheumatic heart disease, have also been reported in some throat carriers. ${ }^{15,16}$ Some authors have also stated an immune response in association with asymptomatic infections. ${ }^{17,18}$

Worldwide estimates for asymptomatic streptococcal throat infections show wide variation. In general, when well children attending outpatient clinics are considered,

\section{(C) 2021. The Author(s).}

This is an open access article published by Thieme under the terms of the Creative Commons Attribution License, permitting unrestricted use, distribution, and reproduction so long as the original work is properly cited. (https://creativecommons.org/licenses/by/4.0/) Georg Thieme Verlag KG, Rüdigerstraße 14, 70469 Stuttgart, Germany 
the rate of BHS carriage is between 2 and $5 \% .{ }^{4}$ However, school studies have been known to show a much wider range with BHS carriage rates between 8 and $40 \% .{ }^{4}$ A meta-analysis of literature published over the past 70 years by Oliver et al puts the GAS throat carriage prevalence rate at $5.9 \%$ (4.3-8.1\%) in low- and middle-income countries, whereas a higher rate of $10.5 \%$ (8.4-12.9\%) has been documented in the developed world. ${ }^{19}$

Studies from Sub-Saharan Africa on streptococcal throat carriage remain relatively rare. In Nigeria, in the last decade, three studies reported rates varying between 4 and $28.9 \%$ for streptococcal throat carriage in children. ${ }^{9,18,20}$ Furthermore, these Nigerian studies have all demonstrated an absence of GAS in asymptomatic carriers despite purportedly high rates of rheumatic fever/rheumatic heart disease in the region. This increase in non-GAS BHS throat carriage has also been reflected in another African study, as well as studies from other parts of the world. ${ }^{7,21-28}$

Streptococcal throat infections are usually treated with a 10-day course of oral penicillin V or amoxicillin. Erythromycin or azithromycin may be used for penicillin-allergic individuals. $^{29-31}$ Though macrolide resistance has been widely reported especially with erythromycin and bacteriologic failure occasionally with penicillin, no large community or hospital-based studies have demonstrated in vitro resistance of GAS throat isolates to penicillin. ${ }^{30-35}$

The current study sets out to establish the prevalence of asymptomatic streptococcal throat infection and antimicrobial susceptibility patterns in school-aged children in Uyo, Southern Nigeria.

\section{Methods}

The current study was performed in Uyo, a city with six political wards located in the Nigerian rainforest at an altitude of $70 \mathrm{~m}$ above sea level and with average annual rainfall of $2,509 \mathrm{~mm}^{36}$

Written permission to carry out the study was obtained from the Akwa Ibom State Ministry of Education. Ethical clearance for the study was obtained from the Institutional Health Research and Ethics Committee of University of Uyo Teaching Hospital. Written/informed consent was obtained from all parent(s)/guardian(s) before recruiting their children into the study.

The study was performed between September 2017 and February 2018, which would correspond to the late rainy season and dry season in the study area.

Sample size was determined by using Fisher's formula applied to study populations greater than $10,000 .^{37}$ The total number of enrolled pupils in primary schools in Uyo was 71,659 making the formula appropriate.

\section{$\mathrm{Z}^{2} \mathrm{PQ} / \mathrm{D}^{2}$}

Where:

$\mathrm{N}=$ minimum sample size

$\mathrm{Z}=1.96$
$\mathrm{D}=$ total width of the expected confidence interval (set at 0.05)

$\mathrm{P}=$ prevalence from similar study at a nearby location $^{18}=20.6 \%$

$\mathrm{Q}=1-\mathrm{P}$

Therefore:

$$
\mathrm{N}=1.96^{2} \times(0.206 \times 0.794) / 0.05^{2}=251
$$

An attrition rate of $10 \%$ was assumed, and thus, the total number of subjects enrolled in the study was 276 .

Primary school students aged 6 to 12 years, whose parents gave consent, were enrolled in the study. Children with symptoms of acute pharyngitis or those who had used antibiotics in 2 weeks preceding the study were excluded.

\section{Sampling Method}

A multistage sampling method was used to recruit for the study. Overall, 12 schools, that is, two per political ward were selected from the 55 schools ( 15 public and 40 private) in the Uyo metropolis. Four public and eight private schools were selected to achieve proportionate representation from the schools. These schools were selected by simple random sampling using the table of random numbers.

The number of pupils selected from each of the 12 schools was determined by proportionate sampling in the second stage. The school sample size was determined by using the formula ${ }^{9}$ :

$$
\mathrm{N} 2=\mathrm{a} \times \mathrm{N} 1 / \mathrm{n}
$$

Where:

$\mathrm{N} 2$ = number of pupils recruited from a given primary school

$\mathrm{a}=$ population of index school

$\mathrm{n}=$ total number of pupils in all the selected primary schools

$\mathrm{N} 1=$ total sample size

In each school, one arm of each class was selected randomly for the study by using the ballot method. ${ }^{38}$ The number of pupils obtained from the chosen arm in a given school was calculated by using the class population (all arms), the school population, and the school sample size as calculated. The calculated sample size of each school (N2) was then distributed proportionately among the classes by using the formula9 ${ }^{9}$ :

$$
\mathrm{N} 3=\mathrm{a} \times \mathrm{N} 2 / \mathrm{b}
$$

Where:

N3 = class sample size

$\mathrm{a}=$ class population (all arms)

$\mathrm{b}=$ population of all classes in the school

N2 = school sample size

The first pupil was randomly selected from the list of pupils in that class by using the ballot method. ${ }^{38}$ All subsequent pupils recruited were then selected by using a systematic sampling method. The list of pupils in the class was 
arranged alphabetically, and this was used as the sampling frame. The selected pupils were then given consent forms for their parents and were only recruited into the study after the filled and signed consent forms had been retrieved from their parents/guardians.

For each recruited pupil, a proforma containing relevant biodata, household number, and physical examination findings was filled out. The family socioeconomic status was determined by using the method described earlier by Olusanya et al. ${ }^{39}$

Throat swabs were taken by using strict aseptic technique. Subjects were asked to open their mouths wide and say "ah." With their mouths open, a throat swab was taken from each participant by gently rubbing the swab stick on the posterior pharynx and tonsillar bed, after depressing the back of the tongue with a wooden spatula. The swab stick was then returned to its sterile container, properly labeled and transported within an hour of collection to the University of Uyo Teaching Hospital laboratory for immediate plating on 5\% sheep blood agar. ${ }^{40}$ Cultures were incubated at $35^{\circ} \mathrm{C}$ for 24 hours in a $\mathrm{CO}_{2}$ jar to enhance growth. Growth of pinpoint colonies with clear surrounding zones of hemolysis ( $\beta$ hemolysis) was identified and the presence of Streptococci was confirmed by a negative catalase test, while a gram stain was processed concomitantly to identify the characteristic grampositive cocci in chains under the microscope.

The identified BHS were then subcultured for purity and inoculated with Bacitracin 0.04U discs for the appropriate identification of GAS. The Lancefield group was subsequently determined from positive cultures by using Oxoid Streptococcal Grouping Latex Agglutination Kit, UK to identify Groups A, B, C, D, F, and G streptococci. Antimicrobial susceptibility testing was done by using the disk diffusion method. ${ }^{38}$ Isolated organisms were cultured on MuellerHinton agar with 5\% Sheep Blood with antibiotic susceptibility discs and incubated for 24 hours at $37^{\circ} \mathrm{C}$. Oxoid UK sterile paper discs containing penicillin $\mathrm{V}(10 \mu \mathrm{g})$, amoxicillin (30 $\mu \mathrm{g})$, erythromycin $(15 \mu \mathrm{g})$, cefuroxime $(30 \mu \mathrm{g})$, co-trimoxazole $(1.25 / 23.75 \mu \mathrm{g})$, and clindamycin $(2 \mu \mathrm{g})$ were used.

The data was analyzed by using the Statistical Package for Social Science for Windows (SPSS Inc Chicago Illinois, United States), version 20. The prevalence of BHS carriage was determined by using simple percentages. Results were reported in text, tables, and figures. Categorical data were recorded as frequencies and percentages, while continuous variables were recorded as means ( \pm standard deviation). Pearson's Chi-square statistical test of significance or Fisher's exact test was used as required to determine the relevant associations between throat carriage and the sociodemographic variables. The level of significance was set at $p<0.05$.

\section{Results}

Two hundred and seventy-six children aged 6 to 12 years were recruited in the study. The mean age of subjects was $8.7 \pm 1.7$ years. Overall, 133 (48\%) were males and 143 (52\%) were females, with a male to female (M:F) ratio of 1:1.1. - Table 1 shows the sociodemographic characteristics of the study group.
Table 1 Sociodemographic characteristics of study population

\begin{tabular}{|c|c|c|}
\hline Characteristic & $\begin{array}{l}\text { Frequency } \\
(n=276)\end{array}$ & Percentage (\%) \\
\hline \multicolumn{3}{|l|}{ Age $(y)$} \\
\hline $6-7$ & 70 & 25.4 \\
\hline $8-9$ & 114 & 41.3 \\
\hline $10-12$ & 92 & 33.3 \\
\hline Total & 276 & 100.0 \\
\hline \multicolumn{3}{|l|}{ Gender } \\
\hline Male & 133 & 48.2 \\
\hline Female & 143 & 51.8 \\
\hline Total & 276 & 100.0 \\
\hline \multicolumn{3}{|l|}{ Household size } \\
\hline$\leq 3$ & 31 & 11.2 \\
\hline $4-6$ & 156 & 56.6 \\
\hline $7-9$ & 73 & 26.4 \\
\hline $10-11$ & 8 & 2.9 \\
\hline$>11$ & 8 & 2.9 \\
\hline Total & 276 & 100.0 \\
\hline \multicolumn{3}{|l|}{ Religion } \\
\hline Christian & 274 & 99.3 \\
\hline Muslim & 2 & 0.7 \\
\hline Total & 276 & 100.0 \\
\hline \multicolumn{3}{|l|}{ Social class } \\
\hline Class 1 & 11 & 4.0 \\
\hline Class 2 & 75 & 27.2 \\
\hline Class 3 & 82 & 29.7 \\
\hline Class 4 & 84 & 30.4 \\
\hline Class 5 & 24 & 8.7 \\
\hline Total & 276 & 100.0 \\
\hline
\end{tabular}

Table 2 Lancefield grouping of $\beta$-hemolytic streptococcal Isolates

\begin{tabular}{|l|l|l|}
\hline Lancefield group & Frequency $(\boldsymbol{n})$ & Percentage (\%) \\
\hline C & 8 & 88.9 \\
\hline G & 1 & 11.1 \\
\hline Total & 9 & 100.0 \\
\hline
\end{tabular}

$\beta$-hemolytic streptococci (BHS) were identified in 9 out of 276 subjects by giving a prevalence of $3.3 \%$.

- Table 2 shows the Lancefield grouping of the BHS isolates. Eight out of nine isolates $(88.9 \%)$ were group $C$ streptococcus and one was group $\mathrm{G}$ streptococcus.

- Table 3 demonstrates the association between sociodemographic factors and BHS throat carriage. The association between age groups and streptococcal throat carriage 
Table 3 Association of sociodemographic factors with asymptomatic $\beta$ - hemolytic streptococcal throat infection

\begin{tabular}{|c|c|c|c|c|}
\hline \multirow[t]{2}{*}{ Characteristic } & \multicolumn{2}{|c|}{$\begin{array}{l}\beta \text {-hemolytic streptococcal throat } \\
\text { infection }\end{array}$} & \multirow[t]{2}{*}{ Total (\%) } & \multirow[t]{2}{*}{ Fisher's exact test ( $p$-value) } \\
\hline & Positive (\%) & Negative (\%) & & \\
\hline \multicolumn{5}{|l|}{ Age } \\
\hline $6-7 y$ & $5(55.6)$ & $65(24.3)$ & $70(25.4)$ & \multirow[t]{3}{*}{$6.47(0.04)^{a}$} \\
\hline $8-9$ y & $4(44.4)$ & $110(41.2)$ & $114(41.3)$ & \\
\hline $10-12$ y & $0(0)$ & $92(34.5)$ & $92(33.3)$ & \\
\hline Total & $9(100)$ & $267(100)$ & $276(100)$ & \\
\hline \multicolumn{5}{|l|}{ Gender } \\
\hline Male & $3(33.3)$ & $130(48.7)$ & $133(48.2)$ & \multirow[t]{2}{*}{$0.82(0.37)^{a}$} \\
\hline Female & $6(66.7)$ & $137(51.3)$ & $143(51.8)$ & \\
\hline Total & $9(100)$ & $267(100)$ & $276(100)$ & \\
\hline \multicolumn{5}{|l|}{ Religion } \\
\hline Christian & $9(100)$ & $265(99.3)$ & $274(99.3)$ & \multirow[t]{2}{*}{$0.01(0.99)^{a}$} \\
\hline Muslim & $0(0)$ & $2(0.7)$ & $2(0.7)$ & \\
\hline Total & $9(100)$ & $267(100)$ & $276(100)$ & \\
\hline \multicolumn{5}{|c|}{ Socioeconomic class } \\
\hline Class 1 & $0(0)$ & $11(4.2)$ & $11(4)$ & \multirow[t]{5}{*}{$4.03(0.40)^{\mathrm{a}}$} \\
\hline Class 2 & $1(11.1)$ & $74(27.7)$ & $75(27.2)$ & \\
\hline Class 3 & $3(33.3)$ & $79(29.6)$ & $82(29.7)$ & \\
\hline Class 4 & $5(55.6)$ & $79(29.6)$ & $84(30.4)$ & \\
\hline Class 5 & $0(0)$ & $24(9)$ & $24(8.7)$ & \\
\hline Total & $9(100)$ & $267(100)$ & $276(100)$ & \\
\hline \multicolumn{5}{|l|}{ Household size } \\
\hline$\leq 3$ & $1(11.1)$ & $30(11.2)$ & $31(11.3)$ & \multirow[t]{5}{*}{$13.31(0.01)^{\mathrm{a}}$} \\
\hline $4-6$ & $3(33.3)$ & $153(57.3)$ & $156(56.6)$ & \\
\hline $7-9$ & $3(33.3)$ & $70(26.2)$ & $73(26.3)$ & \\
\hline $10-11$ & $2(22.3)$ & $6(2.3)$ & $8(2.9)$ & \\
\hline$>11$ & $0(0)$ & $8(3.0)$ & $8(2.9)$ & \\
\hline Total & $9(100)$ & $267(100)$ & $276(100)$ & \\
\hline
\end{tabular}

${ }^{\text {a}}$ Fisher's exact test was used.

was statistically significant $(p=0.04)$. Despite a noticeably higher throat carriage rate in females (66.7\%), the difference was not statistically significant $(p=0.37)$. The number of household occupants demonstrated a statistically significant association with asymptomatic BHS infection. Religion and social class did not show a significant relationship with streptococcal throat carriage.

- Table 4 shows the antibiotic susceptibility of BHS isolates. Just over three-quarters of the isolates were susceptible to penicillin, and only one-third to amoxicillin. Susceptibility was best with cefuroxime and clindamycin. None of the isolates showed sensitivity to co-trimoxazole. A significantly higher proportion of the streptococcal isolates in the children demonstrated susceptibility to cefuroxime and clindamycin.

\section{Discussion}

The BHS carriage rate in our study, though slightly lower than the mean rate of $5.6 \%$ reported in low and middle-income countries worldwide, compares favorably with the prevalence of $4 \%$ reported by Baki et al in Calabar, Nigeria. ${ }^{19,20}$ This can be probably explained by the fact that both cities share similar sociocultural characteristics. An earlier study in Calabar, Nigeria $^{18}$ had recorded a much higher prevalence rate of $20.9 \%$. This could be justified by their sample collection over a 1-year period as compared with the current study, which was done toward the end of the rainy season and in the dry season. The former study would also have been able to consider seasonal variations over an entire year, thus resulting in a higher prevalence. Our finding also compares favorably with 
e32 Streptococcal Throat Carriage among Children Edem et al.

Table 4 Lancefield group-specific antibiotic susceptibilities of beta-hemolytic streptococcal isolates

\begin{tabular}{|c|c|c|c|c|c|}
\hline \multirow[t]{2}{*}{ Antibiotic } & \multirow[t]{2}{*}{ Susceptibility pattern } & \multicolumn{2}{|c|}{ Lancefield group } & \multirow[t]{2}{*}{ Total (\%) } & \multirow[t]{2}{*}{ Fisher's exact ( $p$-value) } \\
\hline & & Group C (\%) & Group G (\%) & & \\
\hline \multirow[t]{2}{*}{ Penicillin } & Sensitive & $6(75)$ & $1(100)$ & $7(77.8)$ & \multirow[t]{2}{*}{$2.77(0.10)^{\mathrm{a}}$} \\
\hline & Resistant & $2(25)$ & $0(0)$ & $2(22.2)$ & \\
\hline \multirow[t]{2}{*}{ Amoxicillin } & Sensitive & $2(25)$ & $1(100)$ & $3(33.3)$ & \multirow[t]{2}{*}{$1.00(0.32)^{\mathrm{a}}$} \\
\hline & Resistant & $6(75)$ & $0(0)$ & $6(66.7)$ & \\
\hline \multirow[t]{2}{*}{ Erythromycin } & Sensitive & $4(50)$ & $1(100)$ & $5(56.6)$ & \multirow[t]{2}{*}{$0.11(0.74)^{\mathrm{a}}$} \\
\hline & Resistant & $4(50)$ & $0(0)$ & $4(44.4)$ & \\
\hline \multirow[t]{2}{*}{ Cefuroxime } & Sensitive & $7(87.5)$ & $1(100)$ & $8(88.9)$ & \multirow[t]{2}{*}{$5.44(0.02)^{\mathrm{a}}$} \\
\hline & Resistant & $1(12.5)$ & $0(0)$ & $1(11.1)$ & \\
\hline \multirow[t]{2}{*}{ Cotrimoxazole } & Sensitive & $0(0)$ & $0(0)$ & $0(0)$ & \multirow[t]{2}{*}{$\mathrm{Nil}^{\mathrm{b}}$} \\
\hline & Resistant & $8(100)$ & $1(100)$ & $9(100)$ & \\
\hline \multirow[t]{2}{*}{ Clindamycin } & Sensitive & $7(87.5)$ & $1(100)$ & $8(88.9)$ & \multirow[t]{2}{*}{$5.44(0.02)^{\mathrm{a}}$} \\
\hline & Resistant & $1(12.5)$ & $0(0)$ & $1(11.1)$ & \\
\hline
\end{tabular}

aFisher's exact test was used.

${ }^{b}$ Null values not appropriate for statistical testing.

the $4.6 \%$ reported by Singh et al in Northern India. ${ }^{22}$ It was however significantly lower than rates (20.9-28.9\%) reported from earlier Nigerian studies. ${ }^{9,18}$ The difference may be due to improved measures for control of respiratory infections, such as better hand hygiene and increased rates of exclusive breastfeeding in the country over the years. ${ }^{41}$ Moreover, several authors have acknowledged wide variations in the prevalence rate of BHS carriage, even within localities in the same regional boundaries. ${ }^{4,9,19}$ This variation may reflect differences in the burden of streptococcal diseases in various localities.

The pattern of BHS isolates from the present study is consistent with that of recent Nigerian studies, which also reported GCS as the commonest BHS isolate in asymptomatic children. ${ }^{9,18,20}$ These earlier reports had also noted a comparable absence of GAS in studies of BHS carriage. In contrast, an earlier study performed in Lagos in 1972 documented GGS as the commonest Lancefield group isolate. ${ }^{42}$ GAS was isolated in $22 \%$ of the children sampled. Changes in the burden of streptococcal diseases in the country over the years may explain the change in pattern of BHS carriage.

The current study found BHS throat carriage rate to be highest in 6 to 7 years age group. This is consistent with the well-documented knowledge about BHS carriage that peaks in the early school age and falls toward adolescence. ${ }^{11}$ It also compares well with a study in Northern India, which showed the highest prevalence in the 5 to 7 years age group. ${ }^{7}$ However, the latter study reported the lowest carriage rates among the 7 to 9 years age group, which had the second highest carriage rate in our study. ${ }^{7}$ Furthermore, while no BHS isolates were found in children aged 10 to 12 years in our study, Baki et al (Calabar) reported the highest carriage rate (36.8\%) in the same age group. ${ }^{20}$ A possible change in the epidemiologic pattern of BHS diseases within the region may account for this difference.
More females than males in the study were streptococcal throat carriers. This is similar to many other studies showing a slight female preponderance in BHS throat carriage, though this difference has usually not been proven to be statistically significant. $9,21,30,33$ This gender disparity may be attributed to a genetic predisposition of females in the study to the dominant "emm" type, which has been also reported in a recent Norwegian study. ${ }^{43}$

Children from households with four to nine occupants were most likely to be BHS throat carriers in the current study. This association could be explained by the fact that children from larger households are more likely to live in overcrowded homes with poor ventilation. Both overcrowding and poor ventilation are associated with streptococcal diseases. ${ }^{44}$ This finding is similar to earlier studies by Owobu et $\mathrm{al}^{9}$ in Benin, and Nayiga et $\mathrm{al}^{21}$ in Uganda who found that BHS carriage rates were higher in children from households with a larger number of occupants.

Overall, $78 \%$ of BHS isolates in the current study were susceptible to penicillin. This finding was lower than the $100 \%$ susceptibility to penicillin earlier reported for BHS. 5,26,30,32 This may be explained by the fact that no GAS was isolated in the current study. Previous studies with GAS have not demonstrated in vitro resistance to penicillin, although an Egyptian study had reported evolving resistance of GAS isolates to penicillin. ${ }^{30}$ The finding that all the BHS isolates in the current study were resistant to cotrimoxazole compared well with findings from an earlier study. ${ }^{7}$ The $100 \%$ resistance of BHS isolates to co-trimoxazole may be explained by the fact that it is a common over-thecounter remedy for sore throat in the country. The routine use of the drug in Pneumocystis carinii pneumonia prophylaxis for all patients with HIV infection may also be a factor in the development of high-grade resistance to the drug as has 
been suggested by other studies. ${ }^{45}$ The ease of access to antibiotics generally, in the study area as well as entire country, may also account for the high resistance of isolates to co-trimoxazole, amoxicillin, and erythromycin.

The 3.3\% prevalence of asymptomatic streptococcal throat carriage recorded in school-aged children in the study is relatively low. The absence of any GAS isolates suggests a low burden of GAS disease in the study area. It is recommended that larger, multicenter studies be conducted to elucidate the changing epidemiology of BHS diseases in the region.

\section{Limitations of the Study}

- This study was only conducted in school-aged children in Uyo. Studies across all ages of children may have an added advantage.

- It was often a challenge to confirm the use of antibiotics in the two weeks preceding the study, in some of the younger children.

- The low numbers obtained from the study made statistical analysis challenging.

Funding

None.

Conflict of Interest

None declared.

\section{References}

1 WHO. The World Health Report 2004. Geneva: WHO; 2005

2 Seale AC, Davies MR, Anampiu K, et al. Invasive group A streptococcus infection among children, rural Kenya. Emerg Infect Dis 2016;22(02):224-232

3 Walker MJ, Barnett TC, McArthur JD, et al. Disease manifestations and pathogenic mechanisms of Group A Streptococcus. Clin Microbiol Rev 2014;27(02):264-301

4 DeMuri GP, Wald ER. The group A streptococcal carrier state reviewed: still an enigma. J Pediatric Infect Dis Soc 2014;3(04): 336-342

5 Shulman ST, Bisno AL, Clegg HW, et al;Infectious Diseases Society of America. Clinical practice guideline for the diagnosis and management of group A streptococcal pharyngitis: 2012 update by the Infectious Diseases Society of America. Clin Infect Dis 2012; 55(10):e86-e102

6 Ann Maes J. Acute pharyngitis in children A2 - Bajaj, Lalit. In: Hambidge SJ, Kerby G, Nyquist AC, eds. Berman's Pediatric Decision Making. 5th ed. St Louis: Mosby; 2011:150-154

7 Devi U, Borah PK, Mahanta J. The prevalence and antimicrobial susceptibility patterns of beta-hemolytic streptococci colonizing the throats of schoolchildren in Assam, India. J Infect Dev Ctries 2011;5(11):804-808

8 Cockerill FR III, MacDonald KL, Thompson RL, et al. An outbreak of invasive group A streptococcal disease associated with high carriage rates of the invasive clone among school-aged children. JAMA 1997;277(01):38-43

9 Owobu AC, Sadoh WE, Oviawe O. Streptococcal throat carriage in a population of nursery and primary school pupils in Benin City, Nigeria. Niger J Paediatr 2013;40(04):389-394

10 Shet A, Kaplan E. Addressing the burden of group A streptococcal disease in India. Indian J Pediatr 2004;71(01):41-48

11 Hayden GF, Turner RB. Acute pharyngitis. In: Kliegman R, Stanton B, Behrman R, St Geme J, Schor N, eds. Nelson Textbook of
Pediatrics. 19th ed New York: Elsevier/Saunders; 2011: 1439-1440

12 Maness DL, Martin M, Mitchell G. Poststreptococcal illness: recognition and management. Am Fam Physician 2018;97(08): $517-522$

13 Sims Sanyahumbi A, Colquhoun S, Wyber R, Carapetis JR. Global disease burden of group A Streptococcus. In: Ferretti JJ, Stevens DL, Fischetti VA, eds. Streptococcus Pyogenes: Basic Biology to Clinical Manifestations. Oklahoma City, OK: University of Oklahoma Health Sciences Center; 2016

14 Rossi E, Felici AR, Banteyrga L. Subclinical rheumatic heart disease in an Eritrean high-school population, detected by echocardiography. J Heart Valve Dis 2014;23(02):235-239

15 Hahn RG, Knox LM, Forman TA. Evaluation of poststreptococcal illness. Am Fam Physician 2005;71(10):1949-1954

16 Gerber MA, Baltimore RS, Eaton CB, et al. Prevention of rheumatic fever and diagnosis and treatment of acute Streptococcal pharyngitis: a scientific statement from the American Heart Association Rheumatic Fever, Endocarditis, and Kawasaki Disease Committee of the Council on Cardiovascular Disease in the Young, the Interdisciplinary Council on Functional Genomics and Translational Biology, and the Interdisciplinary Council on Quality of Care and Outcomes Research: endorsed by the American Academy of Pediatrics. Circulation 2009;119(11):1541-1551

17 Ozturk CE, Yavuz T, Kaya D, Yucel M. The rate of asymptomatic throat carriage of group A Streptococcus in school children and associated ASO titers in Duzce, Turkey. Jpn J Infect Dis 2004;57 (06):271-272

18 Mandor BI, Asuquo AE, Abia-Bassey L, et al. Antistreptolysin O (ASO) titers and Beta-haemolytic streptococcus (BHS) in children in Calabar, Nigeria. IOSR J Nurs Health Sci 2013;1(05):42-46

19 Oliver J, Malliya Wadu E, Pierse N, Moreland NJ, Williamson DA, Baker MG. Group A Streptococcus pharyngitis and pharyngeal carriage: a meta-analysis. PLoS Negl Trop Dis 2018;12(03):e0006335

20 Baki IM, Pièrre TL, Asuquo A, Ogba O. Assessment of beta haemolytic streptococci carriage among school children in Calabar, Nigeria. Adv Biomed Pharma 2015;2(06):283-288

21 Nayiga I, Okello E, Lwabi P, Ndeezi G. Prevalence of group a streptococcus pharyngeal carriage and clinical manifestations in school children aged 5-15 yrs in Wakiso District, Uganda. BMC Infect Dis 2017;17(01):248

22 Singh AK, Kumar A, Agarwal L, Agarwal A, Sengupta C. Prevalence of group A streptococcal pharyngitis among schoolchildren of Barabanki district, Uttar Pradesh, India. J Acad Clin Microbiol 2015;17(02):110

23 Oppegaard O, Mylvaganam H, Kittang BR. Beta-haemolytic group A, C and G streptococcal infections in Western Norway: a 15year retrospective survey. Clin Microbiol Infect 2015;21(02): 171-178

24 Bramhachari PV, Kaul SY, McMillan DJ, Shaila MS, Karmarkar MG, Sriprakash KS. Disease burden due to Streptococcus dysgalactiae subsp. equisimilis (group $\mathrm{G}$ and $\mathrm{C}$ streptococcus) is higher than that due to Streptococcus pyogenes among Mumbai school children. J Med Microbiol 2010;59(Pt 2):220-223

25 Tartof SY, Farrimond F, de Matos JA, et al. Inverse association between Lancefield group G Streptococcus colonization and sore throat in slum and nonslum settings in Brazil. J Clin Microbiol 2011;49(01):409-412

26 Delpech G, Sparo M, Baldaccini B, Pourcel G, Lissarrague S, García Allende $\mathrm{L}$. Throat carriage rate and antimicrobial resistance of Streptococcus pyogenes in rural children in Argentina. J Prev Med Public Health 2017;50(02):127-132

27 Menon T, Shanmugasundaram S, Kumar MP, Kumar CP. Group A streptococcal infections of the pharynx in a rural population in south India. Indian J Med Res 2004;119(Suppl):171-173

28 Steer AC, Jenney AW, Kado J, et al. Prospective surveillance of streptococcal sore throat in a tropical country. Pediatr Infect Dis J 2009;28(06):477-482 
29 Armstrong C. AHA guidelines on prevention of rheumatic fever and diagnosis and treatment of acute streptococcal pharyngitis. Am Fam Physician 2010;81(03):346

30 Abd El-Ghany SM, Abdelmaksoud AA, Saber SM, Abd El Hamid DH. Group A beta-hemolytic streptococcal pharyngitis and carriage rate among Egyptian children: a case-control study. Ann Saudi Med 2015;35(05):377-382

31 Martin JM, Green M, Barbadora KA, Wald ER. Erythromycinresistant group A streptococci in schoolchildren in Pittsburgh. N Engl J Med 2002;346(16):1200-1206

32 Jain A, Shukla VK, Tiwari V, Kumar R. Antibiotic resistance pattern of group-a beta-hemolytic streptococci isolated from north Indian children. Indian J Med Sci 2008;62(10): 392-396

33 Raza S, Kundu K, Dutta S. Prevalence of asymptomatic pharyngeal carriage of B-hemolytic Group A Streptococcus pyogenes among school going children of age 5-12 years in Bharatpur, Nepal. J Kathmandu Med Coll 2014;2(01):3

34 Casey JR, Pichichero ME. Meta-analysis of cephalosporin versus penicillin treatment of group A streptococcal tonsillopharyngitis in children. Pediatrics 2004;113(04):866-882

35 Casey JR. Selecting the optimal antibiotic in the treatment of group A beta-hemolytic streptococci pharyngitis. Clin Pediatr (Phila) 2007;46:25S-35S

36 Climate: Uyo Accessed July 12, 2019 at: http://en.climate-data.org/location/4733/

37 Araoye MO. Research Methodology with Statistics for Health and Social Science. Ilorin: Nathadex Publishers; 2004: 115-129
38 Jorgensen JH, Ferraro MJ, Jorgensen JH, Ferraro MJ. Antimicrobial susceptibility testing: a review of general principles and contemporary practices. Clin Infect Dis 2009;49(11): 1749-1755

39 Olusanya O, Okpere E, Ezimokhai M. The importance of socioeconomic class in voluntary fertility control in a developing country. West Afr J Med 1985;4:205-212

40 Miller J, Krisher K, Holmes H. General principles of specimen collection and handling. In: Murray PR, Baron EJ, Jorgensen JH, et al, eds. Manual of Clinical Microbiology. 9th ed. Washington DC: ASM Press; 2004:43-52

41 National Population Commission (NPC) [Nigeria] and ICF 2019. Nigeria Demographic and Health Survey 2018 Key Indicators Report. Rockville, MD: NPC and ICF; 2019:37

42 Ogunbi O, Fadahunsi HO, Ahmed I, et al. An epidemiological study of rheumatic fever and rheumatic heart disease in Lagos. J Epidemiol Community Health 1978;32(01):68-71

43 Meisal R, Andreasson IK, Høiby EA, Aaberge IS, Michaelsen TE, Caugant DA. Streptococcus pyogenes isolates causing severe infections in Norway in 2006 to 2007: emm types, multilocus sequence types, and superantigen profiles. J Clin Microbiol 2010; 48(03):842-851

44 Carapetis JR, Steer AC, Mulholland EK, Weber M. The global burden of group A streptococcal diseases. Lancet Infect Dis 2005;5(11):685-694

45 Marwa KJ, Mushi MF, Konje E, Alele PE, Kidola J, Mirambo MM Resistance to cotrimoxazole and other antimicrobials among isolates from HIV/AIDS and non-HIV/AIDS patients at Bugando Medical Centre, Mwanza, Tanzania. Aids Res Treat 2015;2015:103874 